\title{
Qualification of a Hybrid Propulsion System for the Mars Ascent Vehicle
}

\author{
Andrew Prince \\ NASA Marshall Space Flight Center \\ Mail Code: ER51 \\ Huntsville, AL 35812 \\ 256-544-6272 \\ andrew.s.prince@nasa.gov \\ Ashley Karp \\ Jet Propulsion Laboratory, California \\ Institute of Technology \\ 4800 Oak Grove Drive \\ Pasadena, CA 91109 \\ 818-354-6322 \\ ashley.c.karp@jpl.nasa.gov
}

\author{
George Story \\ NASA Marshall Space Flight Center \\ Mail Code: ER51 \\ Huntsville, AL 35812 \\ 256-544-6272 \\ george.story@nasa.gov
}

\author{
Britt Oglesby \\ NASA Marshall Space Flight Center \\ Mail Code: ER51 \\ Huntsville, AL 35812 \\ 256-961-2398 \\ britt.a.oglesby@,nasa.gov
}

\begin{abstract}
Technology for a hybrid based propulsion system is being developed to support a potential Mars Sample Return campaign. A Mars Ascent Vehicle (MAV) concept for launching samples off of Mars, and delivering them to orbit for further transport to Earth may utilize hybrid propulsion due to the predicted favorable low temperature characteristics and high performance of this option. However, the hybrid option is still undergoing technology development to demonstrate these capabilities. Once development of a capable hybrid propulsion system is proven, further work will be required. This will include environmental testing relative to the mission, and integration with the vehicle reaction control systems and payload. Qualification of such a system will be a significant effort. It will require specialized procurements for the propellants and environments involved, and further testing of the more specialized designs. This paper details an estimate of the tasks required to complete development efforts from Technical Readiness Level 5 (TRL5) through qualification. A success based program was formulated to reach the required performance metrics sufficient for a standard Preliminary Design Review (PDR). Using task level inputs from team members cost and schedule were conceived for continued progress to Critical Design Review (CDR), then through Qualification.
\end{abstract}

\section{TABLE OF ConTents}

1. INTRODUCTION........................................................1

2. HYBRID MOTOR CHALLENGES ..........................2

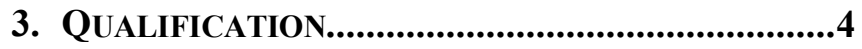

4. ConCluSION ........................................................6

5. ACKNOWLEDGEMENTS......................................7

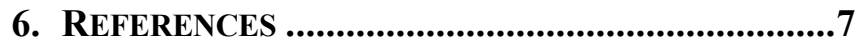

7. BIOGRAPHY …..................................................8

\section{INTRODUCTION}

A key aspect of the proposed NASA Mars Sample Return mission is the Mars Ascent Vehicle (MAV), the vehicle to launch the Martian samples, collected from Mars 2020, from the surface of Mars into Mars orbit. A hybrid motor system is the current propulsion baseline for the MAV, but there are still many challenges to design, test, and qualify a flight system to be used as early as 2026. Currently the hybrid rocket motor is designed to use Mixed oxides of Nitrogen (MON) as the oxidizer, specifically MON30 where 30 represents the amount of nitric oxide. The motor also uses paraffin based SP7 as the fuel. The oxidizer and fuel were selected based on the low temperature capability, but have not been adequately characterized. Over the past few years, both subscale and full scale hybrid motors, have been developed and tested. The tests have been in large part successful, but have also identified further challenges that will need to be addressed in the coming years. 

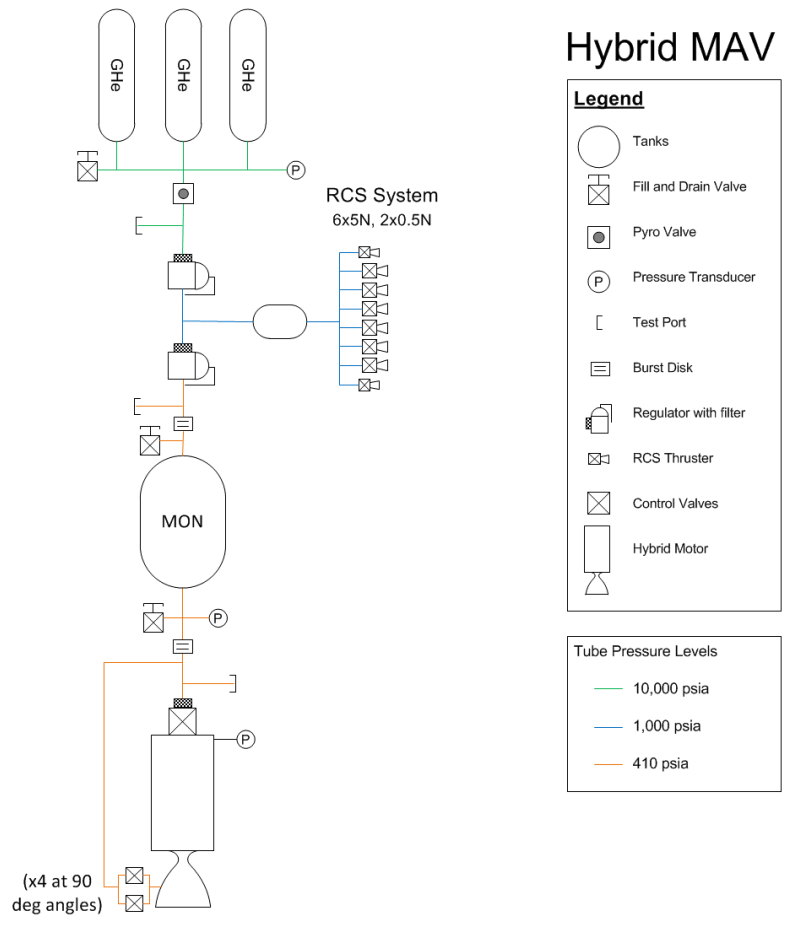

\section{Figure 1 MAV Detailed Design}

The baseline hybrid propulsion system ${ }^{1}$ consists of high pressure helium tanks, with flow being regulated by a high pressure then lower pressure regulator. The helium flow pressurizes the MON oxidizer tank. The oxidizer flows into the motor thru a main valve, injector, and then into the motor. Along the way there are various burst disks and pyro valves to isolate the helium tanks as well as the MON oxidizer during the long assembly, transit and stay time on MARs before the system is ready to operate.

\section{Hybrid Motor Challenges}

\section{Motor Design}

In order to mature the current MAV hybrid motor system several challenges have been identified, with key tasks to tackle them.

The performance of the hybrid motor is a task that will continue to be evaluated throughout development testing as the design is refined. A key performance parameter that has been closely studied is that combustion stability of the motor during testing. The combustion stability is important to efficiently utilize the available fuel, as well as limit the magnitude of any pressure oscillations and the resulting thrust oscillations. One of the causes of combustion instability is believed to be caused by insufficient energy in the forward end of the motor. Various methods have been tested to mixed success. One of the most promising methods of ensuring combustion stability is the addition of TEA/TEB into the forward combustion chamber of the motor.

Although the TEA/TEB has improved the stability of the motor, it also comes at a mass cost to the system. Therefore it is important to minimize the amount of TEA/TEB while still ensuring stability.
The hybrid motor has design goals of certain C-star efficiency, that to date have not been met. Lower C-star efficiency means lower ISP efficiency, and therefore a larger motor to lift the same mass. Some of the low C-star efficiency is due to the higher then desired throat erosion observed in some of the testing to date. That is being reviewed for possible solutions. Nozzle expansion is fixed at this point due to the MAV length requirement of 3 meters. A longer, higher expansion nozzle could help with the ISP, however some designs add complexity with mechanical devices to extend the nozzle $e^{2,3}$ or others that have limited test data ${ }^{4}$ and both techniques would require some development.

Liquid Injection Thrust Vector Control (LITVC) is the current system for steering the hybrid concept. A liquid is injected into the supersonic section of the nozzle, which creates a shock and high pressure on the nozzle side and that force pushes the nozzle in a certain direction. The concept was used on the early Titan solid rocket boosters ${ }^{5}$, with $\mathrm{N} 2 \mathrm{O} 4$ as the injection fluid. While some of that design information is available, there is still development testing to be done. There has been some LITVC analysis done with $\mathrm{CFD}^{6}$ with the full MAV nozzle expansion ratio and some demonstration of the concept in the motor vendor's, Space Propulsion Group (SPG) and Whittinghill Aerospace, tests with smaller expansion ratios. That data is being analyzed. There will be a vacuum test of a hybrid motor with a full expansion cone nozzle in a vacuum chamber at NASA's Whitesands facility to demonstrate the performance in the appropriate environment. Valves may be a challenge for the LITVC, due to low weight requirements and MON compatibility requirements.

In the next year, there are many activities planned to address the risks to the hybrid propulsion MAV concept. Some of these are being done by NASA Ames, Jet Propulsion Laboratory (JPL), Marshall Space Flight Center (MSFC), SPG and Whittinghill Aerospace. Objectives of this year's testing at the motor vendors include minimizing the fuel residuals, increasing C-star efficiency, ISP and lowering the overall motor mass. C-star efficiency will include understanding the nozzle erosion and what can be done to mitigate it. At NASA and the vendors, several CFD models are being generated to help with motor ignition, stability and interior insulator heating environments.

At the end of this development testing period, a flight motor will be manufactured, CT scanned, and put into environmental cycling, similar to what was done in 2016 . $^{7}$ The motor will then be CT scanned again to look for damage compared to the baseline. The motor will be shipped to NASA's Whitesands facility for testing in a vacuum chamber, where the primary objective is LITVC performance in a close to vacuum environment.

There are vehicle level trades also being performed for the hybrid propulsion system. In the past several years the focus has been on the propulsion aspects only. How they package into a vehicle has only been studied peripherally. 
These vehicle level studies will include several design cycles on the hybrid and solid propulsion MAV designs. There is also $400 \mathrm{~kg}$ mass limit requirement on the MAV. All of the propulsion, structural and, controls systems feed into this mass. All components must be watched for mass growth and any areas for mass reduction. As the designs mature they will be run thru trajectory design and analysis for mission verification. Structural components as well as Avionics and Power will be evaluated.

In addition to testing, there are various models being addressed for the hybrid motor performance, propulsion system weights and performance. At the end of this year's testing, modeling, vehicle analysis, there will be a down select between the solid and hybrid propulsion system concepts. Assuming that that hybrid system wins, there will be another round of testing, design and analysis to reduce the system risks.

\section{Hybrid Fuel}

SP7, the paraffin based fuel in the hybrid motor, was developed by SPG and selected for use on the MAV due to the low temperature capability with promising mechanical characteristics ${ }^{8}$. Throughout the previous development cycle, MSFC was responsible for the manufacture of the SP7 fuel grains to be used in the two competing vendors' hybrid motors. The manufacture of the fuel grains has brought on many challenges ${ }^{9}$, many related to the large coefficient of thermal expansion (CTE) of the SP7. As the fuel grain cools after casting it shrinks considerably, inducing residual stress within the cast SP7. This often resulted in fuel segments cracking in ambient cooled grains. The large CTE of the fuel segments also poses challenges of bonding the segments within the liner. The adhesive not only must be flexible enough to expand and shrink with the fuel, but also withstand cold temperatures and bond effectively to the fuel, a challenge in its own right.

The fuel grain manufacturing process has been refined over the past two years 9 . Currently the full size fuel grain is composed of a number of smaller segments. The smaller segments help reduce the residual stress within the fuel grain, as well as reduce the stress caused by thermal cycling within the motor.

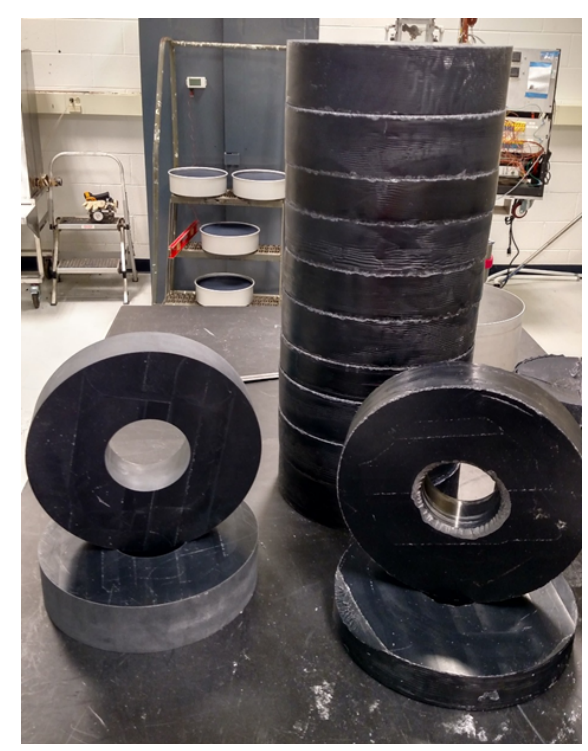

Figure 2 Fuel Grain Segments

Although fuel has been effectively used in a full scale motor test, the fuel will need to undergo further characterization. The residual stress added during the casting process should be further studied to fully understand the state of a fuel grain segment after casting. As part of this effort, Southern Research Inc is testing SP7 to find properties needed for a NASA modeling effort to understand the phase change of and residual stresses in the fuel from different processing cycles.

Once understood, mitigation techniques can also be tested. Although the fuel has undergone preliminary thermal cycling ${ }^{7}$, further testing will also need to be completed, including thermal cycling a full size fuel grain. The mechanical properties of the SP7 will also be characterized in the coming years. It will be important to retest the fuel if the manufacturing process changes during development.

One of the current MAV design calls for the fuel grain to be adhered to a liner that doubles as insulation. The liner, and the adhesive that bonds the fuel to the liner, are important aspects of the loaded fuel grain. The current liner being used, a phenolic tube, has a much lower CTE than the SP7. Therefore when the cartridge is thermally cycled the fuel grain pulls away from the liner. If the adhesive is not flexible enough the fuel grain can completely detach from the liner. The unbonded fuel grain creates the possibly of SP7 chunks being released from the motor near the end of burn. Therefore further development is needed with both the liner and the adhesive. The liner and adhesive material selection and testing has also started at both SPG and MSFC. Promising candidates may be selected and used during near term development tests.

\section{Hybrid Liquid Systems}

Although development has been primarily focused on the fuel and case design of the hybrid motor, the liquid side of the system will also need to be designed and tested. A key aspect of the liquid system design will be the oxidizer, 
currently MON30. MON30 has been studied and utilized in a limited capacity ${ }^{10}$, therefore further characterization is needed. The oxidizer system including the tank, plumbing, regulators, and valves will begin design and development as soon as possible. Many of the components may require long lead times for development as well as procurement.

Procurement of the long lead qualification components will likely occur before CDR. MON typically is very tough on materials, specifically valve seat materials. Long duration use needs to be understood. While there is limited material compatibility and MON property data available, more needs to be generated. There will be work done by NASA's Whitesands facility to address these issues.

The feed system has several challenges to be overcome. The helium tanks are high pressure tanks that must not leak. Typically as pressurant tanks are blown down, the remaining material gets colder and is harder to get out. The current MAV system start temperature is $-20^{\circ} \mathrm{C}$. Heating the Helium tanks to a higher start temperature than the MON30 and SP7 would allow more of the helium to be used in the pressurization of the MON tanks. There are ways to heat the helium during use, but involves more complexity and mass than a simple blowdown system. The higher the pressure in the helium tanks, the higher the handling risk after they are filled, further complicating lander assembly operations. Depending on the final helium tank pressure, the regulators will be unique and large modifications/extrapolations of systems currently in use and may encounter development issues.

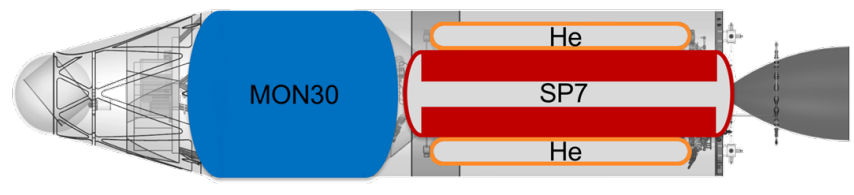

Figure 3 Hybrid MAV Design

The oxidizer tank holds the largest propellant mass, and will be part of the vehicle structure, supporting the returning sample container and the hybrid motor thrust loads. A unique loading condition will be the Earth launch and Mars reentry loads, including the heat shield deceleration and the parachute shock. These loads will be on the vehicle in the horizontal position. There may be limited attach points to support the MAV during these phases and these could drive the oxidizer tank design.

The oxidizer valve will need to hold MON pressure during and after the pyro valve are blown until the motor is ready to launch. During ascent there will be two firings of the motor with a 10-15 minute coast between them. The first gets the MAV off the lander and into a highly elliptical orbit. The second circularizes the orbit at apogee. The oxidizer valve needs to contain the MAV during the coast. Another requirement on the oxidizer valve is the desired ignition interval for the hybrid motor. Depending on how the motor is released from the lander, there is a risk of flipping the lander. The current plan is a fast ignition interval to get the MAV quickly away from the lander after a clean release. A quick ignition interval requires a fast acting oxidizer valve and possibly preheating the fuel grain port to ensure the flame doesn't blow out. Testing and analysis will determine what level of ignition interval can be achieved.

Pyro valves will also need to be developed to meet the MAV flowrate, pressure, MON compatibility and environmental requirements and desired leak rates. While these should be similar to other systems, there is development work required.

In order to begin reducing some of the risks of the liquid system, WSTF and Purdue University are beginning work on characterizing MON30. This will include verification of properties at various temperatures as well as material compatibility. The MON feed system components (tanks, valves, regulators, etc) are being specified and these requirements will be discussed with vendors to see what is available. There is also work going on to model MON slosh in a tank with and without baffles. This slosh model, without baffles, has been given to GNC for modeling of the flight dynamics. The vectoring system trade that gave us the LITVC baseline will be reevaluated. Additional inputs for this round include the test data provided by the motor vendors and consultation with the GNC modelers to see if the baseline system can perform as required.

\section{QUALIFICATION}

After the motor has been developed and undergone CDR, it must then be qualified for flight. The rigorous qualification process will be a multi-year progression including qualifying individual components, several static motor firings, and the possibility of a few flight tests. The qualification process will require several full motor builds, therefore procurement and manufacturing will not be a trivial task.

\section{Hybrid Fuel Qualification}

One of the aspects of solid propellant that flows over to hybrids is the need to understand the different ingredients in the motor and how it affects burn rate and structural properties. There can be variations from lot to lot of different chemicals. Typically for solids, A Basis material properties are desired to understand the range of properties from the different ingredients. This normally comes from several lots of materials being tested. The SP7 materials are commercially available, relatively inexpensive and could be bought in bulk for one set of ingredients to be used during the development, qualification and flight motors. Some of the ongoing material research will need to be repeated for the later development, qualification and flight motor materials to ensure there were no changes.

Understanding the casting, cool down and machining process well enough to set the procedures for the rest of the program is desired. Procedures have been developed for 
the processing of SP7, but they are nowhere near as detailed or documented as done in solid rocket motors used for manned space flight. These grain formulation processes will need further documentation and tracking as the program grows. Critical steps will need to be identified and recorded during the manufacturing of the hardware. Measurement of machined SP7 for assembly into the motors should be done in a controlled environment where the temperature can be recorded and dimensions adjusted to a standard temperature.

Solid rocket motors ingredients are typically added to large mix bowls and mixed at certain temperatures and conditions to make the propellant. Depending on the size of the motor, multiple motors are cast or the multiple mixes are poured into one motor case. For each of the mixes, a burn rate motor or motors and fuel samples are cast. The burn rate motors are used to understand the burn rate of the propellant, since it can vary in solid propellants. The fuel samples are used to test the propellant physical properties. Similar processes need to be developed for the hybrid propulsion system. We add, heat and mix the SP7 ingredients in a commercially available wax melter and pump the wax into preheated motor cases in an oven. Small burn rate motors should/could be added to the process. SPG has a small 3 inch motor that has been used for earlier SP7 testing ${ }^{8}$. Another motor that could be used for this is the solid fuel torch motor at $\mathrm{MSFC}^{11}$ however that is set up to use GOX. It could be used to scale the regression rates. Other processes to evaluate the regression might be exposure to a heat gun, or some other less exotic, but qualitative technique to determine the SP7 is mixed properly and regresses the same as the previous materials produced.

\section{Liquid System Component Qualification}

The liquid system will be composed of many individual components that will need to be qualified. The system will consist of components such as the regulators, pyro valves, the main oxidizer valve, RCS valves, LITVC valves, etc. In order to reduce cost and development time of the components, COTs components are desirable, and will therefore reduce the scope of the qualification. However, due to the limited use of MON30, many of the components will be uniquely designed or modified. Therefore the components will need to be uniquely qualified. The components may also undergo qualification throughout the development and testing process. Qualifying individual components before being integrated into a larger system will help reduce the schedule by qualifying multiple components in parallel paths. A large task will be the procurement and qualification of the oxidizer tank. As mentioned previously, the tank with also be a main structural component of the vehicle, therefore additional qualification testing is to be expected. Due to the cost and long procurement time of the tank, it will be essential to ensure the qualification process is planned early.

In addition to qualifying individual components in the system, sub assembly qualification tests may be necessary to test the interaction between components. Testing a subassembly will help test multiple components working together before being integrated into the integrated qualification system. For example, the helium feed to the RCS thrusters and oxidizer tank can be tested together, and the oxidizer tank feeding the motor and LITVC can be tested as a subassembly using a facility pressurant. By testing certain components as sub-assemblies, long lead items such as tanks will not affect the testing of subsystems. Testing components as sub-assemblies will help advance qualification and reduce risk.

\section{Qualification Motors}

A key aspect of the hybrid motor qualification process is static firing full size motors. The qualification motors will consist of the motor and LITVC, but not necessarily the flight oxidizer tank, flight Helium tanks, and RCS system. Due to the range of unique environments the motor will be exposed to, it is important to test the motor under all the conditions it may experience. In order to test the possible scenarios the motor will experience, multiple static tests must be conducted. The greater number of static tests conducted through qualification, the lower the risk of unexpected motor performance. However with each static test comes a cost and schedule impact. Therefore it is important to minimize risk, while still staying within budget and schedule. Currently the recommended number of qualification motor tests is 6 , with the test parameters seen below.

\begin{tabular}{|l|c|c|c|c|c|c|}
\hline \multicolumn{1}{|c|}{ Test } & $\# 1$ & $\# 2$ & $\# 3$ & $\# 4$ & $\# 5$ & $\# 6$ \\
\hline Planetary protection method & $\mathrm{X}$ & $\mathrm{X}$ & $\mathrm{X}$ & $\mathrm{X}$ & $\mathrm{X}$ & $\mathrm{X}$ \\
\hline Acceptance & $\mathrm{X}$ & $\mathrm{X}$ & $\mathrm{X}$ & $\mathrm{X}$ & $\mathrm{X}$ & $\mathrm{X}$ \\
\hline Thermal Cycling & $\mathrm{X}$ & $\mathrm{X}$ & $\mathrm{X}$ & $\mathrm{X}$ & & \\
\hline Mars thermal cycling & $\mathrm{X}$ & & & & $\mathrm{X}$ & $\mathrm{X}$ \\
\hline Aging & & $\mathrm{X}$ & $\mathrm{X}$ & & $\mathrm{X}$ & $\mathrm{X}$ \\
\hline Vibration & & $\mathrm{X}$ & $\mathrm{X}$ & & $\mathrm{X}$ & $\mathrm{X}$ \\
\hline Shock & $\mathrm{X}$ & $\mathrm{X}$ & $\mathrm{X}$ & $\mathrm{X}$ & $\mathrm{X}$ & $\mathrm{X}$ \\
\hline Altitude start & & $\mathrm{X}$ & & $\mathrm{X}$ & $\mathrm{X}$ & $\mathrm{X}$ \\
\hline Ignition function variation - low & & $\mathrm{X}$ & & $\mathrm{X}$ & $\mathrm{X}$ & \\
\hline Ignition function variation - high & $\mathrm{X}$ & & $\mathrm{X}$ & & & $\mathrm{X}$ \\
\hline Low temp function & & $\mathrm{X}$ & & $\mathrm{X}$ & & $\mathrm{X}$ \\
\hline High temp function & $\mathrm{X}$ & & $\mathrm{X}$ & & $\mathrm{X}$ & \\
\hline Short duration & & $\mathrm{X}$ & $\mathrm{X}$ & & $\mathrm{X}$ & $\mathrm{X}$ \\
\hline Long duration & $\mathrm{X}$ & & $\mathrm{X}$ & & & $\mathrm{X}$ \\
\hline Low flow rate & & $\mathrm{X}$ & & $\mathrm{X}$ & $\mathrm{X}$ & \\
\hline High flow rate & & $\mathrm{X}$ & $\mathrm{X}$ & & $\mathrm{X}$ & \\
\hline Short time between restart & $\mathrm{X}$ & $\mathrm{X}$ & $\mathrm{X}$ & $\mathrm{X}$ & $\mathrm{X}$ & $\mathrm{X}$ \\
\hline Long time between restart & & & & & & \\
\hline $2^{\text {nd }}$ ignition function variation - low & & & \\
\hline $2^{\text {nd }}$ ignition function variation - high & & & & & \\
\hline LITVC function & & & & & & \\
\hline
\end{tabular}

\section{Figure 4 Qualification Test Matrix}

The test parameters are essential to qualifying the motor. The motor must perform as expected when on Mars after undergoing various environmental conditions. After undergoing normal motor manufacturing and flight preparations such as planetary protection, the qualifications motor will be exposed to a range of the expected conditions, and then test fired.

Due to the large temperature swings on Mars as the vehicle is awaiting launch, the qualification motors will undergo simulated temperature swings under an accelerated time period. The motors must also be conditioned to $-20^{\circ} \mathrm{C}$ before being fired, the current launch temperature requirement. The qualification matrix also calls for motors tested at below and above nominal temperatures of $-25^{\circ} \mathrm{C}$ 
and $-15^{\circ} \mathrm{C}$. Due to the long duration of the mission, a couple of the motors will also undergo a simulated aging period to test any effects of long term storage.

In addition to the harsh thermal environment on mars, the surface pressure on mars is significantly less, therefore each qualification motor will be fired under near vacuum conditions. This will most likely be done by plugging the motor chamber and pulling a vacuum on it. Testing the relight of the motor for the second burn will be more difficult to test in a hands off manner.

Rocket motors typically experience launch shock, vibrations, and acceleration, however the MAV motor will also have to undergo entry, descent, and landing onto Mars. Therefore a few of the motors will undergo a variety of environmental shock and vibe tests before being test fired for qualification.

The qualification motors must also be tested for any performance deviation. Therefore, the tests will include variation in ignition function on first and second burns, oxidizer flow rate, and the time in between the first and second burn. Throughout the qualification schedule the motors will be exposed to increasingly harsher environments, to ensure the motor will still operate nominally in a worst case scenario.

\section{Integrated System Qualification Motors}

In addition to the qualification motors statically fired, it is recommended that 4 more qualification tests should be conducted with the integrated flight system. This integrated system should be as close to a flight system as reasonable, essentially a flight MAV statically fired. The system qualification tests will ensure there are no unexpected interactions between all of the flight systems. The integrated system will also undergo similar environmental conditioning as seen in the qualification motor tests.

\begin{tabular}{|l|c|c|c|c|}
\hline \multicolumn{1}{|c|}{ Test } & $\# 1$ & $\# 2$ & $\# 3$ & $\# 4$ \\
\hline Acceptance & & & & \\
\hline Mars thermal cycling & & & $\mathrm{X}$ & $\mathrm{X}$ \\
\hline Vibration & & $\mathrm{X}$ & & $\mathrm{X}$ \\
\hline Shock & & $\mathrm{X}$ & & $\mathrm{X}$ \\
\hline Altitude start & $\mathrm{X}$ & $\mathrm{X}$ & $\mathrm{X}$ & $\mathrm{X}$ \\
\hline Low temp function & & $\mathrm{X}$ & & $\mathrm{X}$ \\
\hline High temp function & $\mathrm{X}$ & & $\mathrm{X}$ & \\
\hline Short duration first burn & $\mathrm{X}$ & & & $\mathrm{X}$ \\
\hline Long duration first burn & & $\mathrm{X}$ & $\mathrm{X}$ & \\
\hline LITVC function & $\mathrm{X}$ & $\mathrm{X}$ & $\mathrm{X}$ & $\mathrm{X}$ \\
\hline RCS Functionality & $\mathrm{X}$ & $\mathrm{X}$ & $\mathrm{X}$ & $\mathrm{X}$ \\
\hline Avionics Functionality & $\mathrm{X}$ & $\mathrm{X}$ & $\mathrm{X}$ & $\mathrm{X}$ \\
\hline
\end{tabular}

\section{Figure 5 Integrated System Test Matrix}

Due to the larger integration of all of the systems these tests will come at a larger schedule and cost impact. Therefore the number of tests is limited to four.

\section{Flight Tests}

In addition to a more typical static qualification test, a flight test program has also been proposed. The flight tests would apply to either a solid or hybrid MAV vehicle ${ }^{12}$, depending on the down selection. The flight tests will consist of a balloon system to take the MAV test vehicle to an altitude where it will then be fired. In addition to in-flight motor performance, the flight test will be able to test key operations of the flight system such as staging, RCS, LITVC, and avionics. Below is a notional flight test matrix proposed by JPL, the matrix represents 5 balloon launched flight tests. The flight sequence moves towards a more representative flight vehicle, increasing the intricacy of the test with each flight.

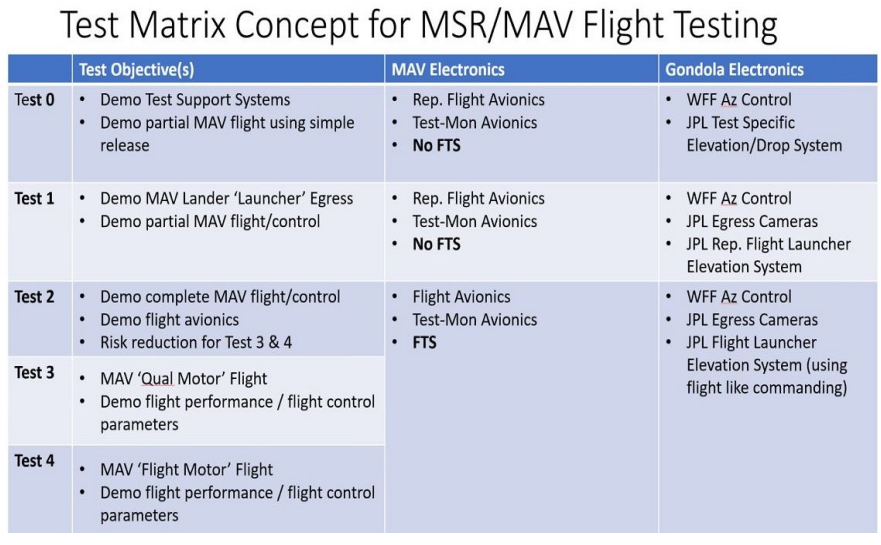

Figure 6 Proposed Flight Test Matrix

The qualification flight tests will be important risk reducing tests, but comes at a large impact to cost and schedule. Although the flight tests are meant to simulate mission conditions, there will still be numerous structures and systems that will be unique to the flight test operations. One of the first challenges moving forward will be to mature tasks and a schedule that incorporates all of the necessary risk reducing activities within the given time remaining before a 2026 launch. The qualification of the hybrid motor will be a balance between development motor static tests, qualification motor static tests, and flight or flight-like tests.

\section{Conclusion}

The MAV hybrid motor continues to do undergo development to become a more mature vehicle. Near and long term risks have been identified with many tasks outlining mitigation techniques. The development and risk reduction has been in large part a collaboration between Ames, JPL, MSFC, SPG and Whittinghill Aerospace. Once the motor has completed CDR, the motor will then begin qualification. The motor will be qualified through a series of component tests, static tests, and flight tests. The tests will put the motor through a variety of expected environmental conditions to fully characterize the flight motor. 


\section{ACKNOWLEDGEMENTS}

\section{REFERENCES}

[1] Ashley Karp, Barry Nakazono, Dave Vaughan, George Story, David Young, Jared Gudenkauf, Jeff West, Robert Moran, Luke Scharber, Will Brandsmeier, "Mars Ascent VehiclePoint of Departure ReviewPropulsion", Dec 14, 2016

[2] C. A. Chase, "Development Status of the IUS Solid Motors", June 30, July 1-2, 1980 AIAA/SAE/ASME 16th JOINT PROPULSION CONFERENCE Hartford, Connecticut, AIAA-1980-1267

[3] Victor Singer, USPatent 4707899, "Method of Making Rocket Motor Extendible Nozzle Exit Cone", Date of Patent Nov 24, 1987

[4] T. E. Kirschner, D. V. Lushis, 0. B. Phillips, 'SHUTTLE-OPTIMIZED SPACE MOTOR

TECHNOLOGY', AIAA-1980-1268

[5] Barnet R. Adelman and Alphonse P. Peters, "Titan III-C, Stage "Zero", AIAA Second Annual Meeting, San Fransico, CA, July 26-29, 1965

[6] Jared Gudenkauf, Jeff West, 'Simulation of Liquid Injection Thrust Vector Control for Mars Ascent Vehicle', AIAA-2017-4999 (ITAR Session)

[7] Edgardo Farias, Matthew Redmond, Ashley Karp, Robert Shotwell, Flora Mechentel and George Story, 'Thermal Cycling for Development of Hybrid Fuel for a Notional Mars Ascent Vehicle', 52nd AIAA/SAE/ASEE Joint Propulsion Conference, July 25-27, 2016, Salt Lake City, UT, AIAA-2016-4563

[8] Brian Evans and Arif Karabeyoglu, "Development and Testing of SP7 Fuel for Mars Ascent Vehicle Application", $53^{\text {rd }}$ AIAA/SAE/ASEE Joint Propulsion Conference, July 10-12, 2017, Atlanta, GA, AIAA-2017-4831

[9] G. T. Story, A. Prince, J. Chaffin, B. Oglesby, T. Kibbey and A. Karp. "Low Temperature Hybrid Mars Ascent Vehicle Concept Development and Planning at MSFC." AIAA Propulsion and Energy Forum, Cincinnati, OH, 2018, July.
[10] Afred C. Wright, 'USAF Propellant Handbooks Nitric Acid/Nitrogen Tetroxide Oxidizers VOL II', AFTPL-TR-7676, February 1977

[11] T. Kibbey, A. Cortopassi, and J. Boyer, "Characterization and Detailed Analysis of Regression Behavior for HTPB Solid Fuels Containing High Aluminum Loadings" $53^{\text {rd }}$ AIAA/SAE/ASEE Joint Propulsion Conference, July 10-12, 2017, Atlanta, GA, AIAA-20174735

[12] A. Prince, R. McCauley, T. Kibbey, L. McCollum, B. Oglesby, P. Stefanski, "Mars Ascent Vehicle (MAV) Solid Motor Technology Plans" 2019 IEEE Aerospace Conference, March 2019, paper \#2126 


\section{BIOGRAPHY}

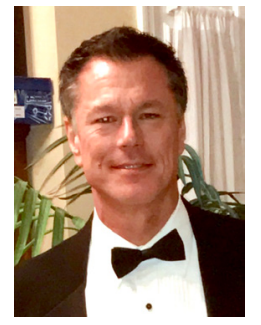

Andrew Prince has worked in the solids and hybrids industry for 30 years with OATK and NASA. He served as the Nozzle Chief Engineer for the Ares $1^{\text {st }}$ stage and was the NASA technical lead for the Orion Launch Abort System. Other efforts include design and manufacture of the Peregrine Sounding Rocket and concept design of the 2015 Mars Ascent Vehicle first stage. Mr. Prince has a patent for a method of composites manufacture and 12 published JANNAF and AIAA papers on material test beds, solids, and hybrid propulsion systems. Currently he is working as propulsion lead for the MARS $2020 \mathrm{MAV}$ vehicle development team at Marshall Space Flight Center.

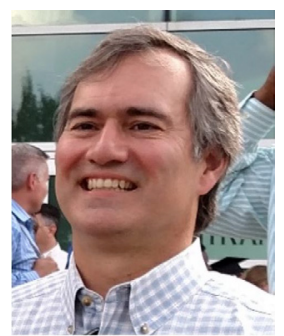

George Story received a B.S. in Aerospace Engineering from North Carolina State in 1988. He is a solid propulsion systems engineer at NASA's Marshall Space Flight Center, before that he was a Martin Marietta/Lockheed Martin. Over the years, he has contributed to multiple solid projects including support of the Space Shuttle Booster Separation Motor and Reusable Solid Rocket Motor, and hybrid rocket programs including Joint IRAD hybrid program and Hybrid Propulsion Demonstration Program. George is a AIAA senior member and a former HRTC chairman and one of many of the committee members that contributed to the HTRC's book 'Fundamentals of Hybrid Rocket Combustion and Propulsion'

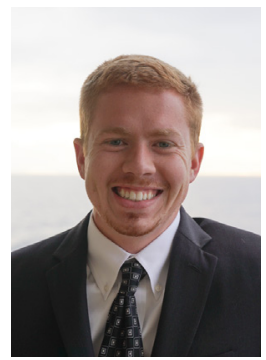

Britt Oglesby received an M.S. in Mechanical and Aerospace Engineering from Oklahoma State University in 2014. Mr. Oglesby worked in the solid propulsion group on the Trident II SLBM before moving to NASA's Marshall Space Flight Center where he has been a member of the Solid Propulsion Design and Analysis division for over a year. During that time he has worked on both hybrid and solid propulsion concepts for the Mars Ascent Vehicle.

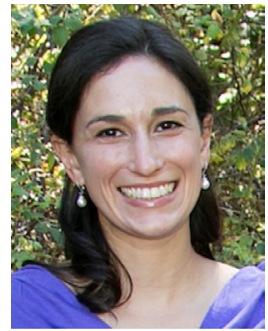

Ashley Chandler Karp earned a Ph.D. in Aeronautics and Astronautics from Stanford University in 2012. She also has a B.A. in Astrophysics, Physics and Political Science from the University of California, Berkeley in 2005. She is currently a Propulsion Engineer at JPL. She is heavily involved in Mars Sample Return technology (especially the Mars Ascent Vehicle and Sample Containment). She is the PI for JPL's Hybrid Propulsion Test Facility. She also works on the Mars 2020 propulsion system. She has also been involved with many mission concept studies. She is the newly elected Vice-Chair of the AIAA Hybrid Rocket Propulsion Technical Committee. 